\title{
Hyperbaric oxygen as an adjunctive therapy in treatment of malignancies, including brain tumours
}

\author{
Katarzyna Stępień ${ }^{1} \cdot$ Robert P. Ostrowski $^{1} \cdot$ Ewa Matyja $^{1}$
}

Received: 30 June 2016/ Accepted: 16 July 2016/Published online: 2 August 2016

(c) The Author(s) 2016. This article is published with open access at Springerlink.com

\begin{abstract}
Hyperbaric oxygen (HBO) therapy is widely used as an adjunctive treatment for various pathological states, predominantly related to hypoxic and/or ischaemic conditions. It also holds promise as an approach to overcoming the problem of oxygen deficiency in the poorly oxygenated regions of the neoplastic tissue. Occurrence of local hypoxia within the central areas of solid tumours is one of the major issues contributing to ineffective medical treatment. However, in anti-cancer therapy, HBO alone gives a limited curative effect and is typically not applied by itself. More often, HBO is used as an adjuvant treatment along with other therapeutic modalities, such as radio- and chemotherapy. This review outlines the existing data regarding the medical use of $\mathrm{HBO}$ in cancer treatment, with a particular focus on the use of $\mathrm{HBO}$ in the treatment of brain tumours. We conclude that the administration of $\mathrm{HBO}$ can provide many clinical benefits in the treatment of tumours, including management of highly malignant gliomas. Applied immediately before irradiation, it is safe and well tolerated by patients, causing rare and limited side effects. The results obtained with a combination of $\mathrm{HBO} /$ radiotherapy protocol proved to be especially favourable compared to radiation treatment alone. HBO can also increase the cytostatic effect of certain drugs, which may render standard chemotherapy more effective. The currently available data support the legitimacy of conducting further research on the use of $\mathrm{HBO}$ in the treatment of malignancies.
\end{abstract}

Katarzyna Stępień

kstepien@imdik.pan.pl

1 Department of Experimental and Clinical Neuropathology, Mossakowski Medical Research Centre, Polish Academy of Sciences, 5 Pawińskiego Str., 02-106 Warsaw, Poland
Keywords Hyperbaric oxygen therapy - Glioblastoma . Cancer $\cdot$ Hypoxia $\cdot$ Radiation therapy $\cdot$ Chemotherapy

\section{Introduction}

Hyperbaric oxygen (HBO) therapy is the use of oxygen under elevated atmospheric pressure, that is, at a pressure higher than the pressure found on the surface of the earth at sea level, which is defined to be $1 \mathrm{~atm}$ [1]. Currently, hyperbaric oxygenation is widely used as an adjunctive treatment for various pathological states, predominantly related to hypoxic and/or ischaemic conditions. The standard protocol for hyperbaric oxygen therapy (HBOT) specifies that patients breathe pure oxygen $(\sim 100 \%)$ under pressure between 1.5 and 2.5 atmospheres absolute (ATA), which is defined as the sum of the atmospheric pressure and the gauge pressure inside the hyperbaric chamber.

Oxygen is transported in blood to tissues by two different, well-known mechanisms: in complex with haemoglobin in red blood cells (RBCs) and dissolved in blood plasma. Under normal atmospheric conditions, almost $97 \%$ of the available haemoglobin is saturated with oxygen. In contrast, plasma typically contains only $0.32 \%$ dissolved oxygen [2]. Thus, the administration of HBO does not have a large effect on oxygen delivery via red blood cells, but may improve haemoglobin-independent transport. HBO has additional beneficial effects, refining the elasticity of RBCs and reducing platelet aggregation, which are especially important when the underlying cause of the tissue hypoxia is cardiovascular in origin [1]. According to Henry's law, if the partial pressure of oxygen $\left(\mathrm{pO}_{2}\right)$ rises, the oxygen content in tissues will also increase [3]. Under higher $\mathrm{pO}_{2}$, the distance that oxygen diffuses is increased. This phenomenon, along with the property that 
oxygen that is dissolved in fluid can reach areas that are inaccessible to RBCs, allows one to imagine that breathing hyperbaric $100 \%$ oxygen may enable more efficient oxygenation of tissues with defective vascularization. HBOT increases the amount of dissolved oxygen in the blood and therefore enhances tissue oxygenation. HBOT has other beneficial biochemical and cellular effects, including reduction in oedema, constriction of blood vessels, activation of phagocytosis, neovascularization, and stimulation of collagen production by fibroblasts. Consequently, HBO finds application in the management of various pathological states [3, 4]. Its beneficial role has been well established in treatment of ischaemia and reperfusion injury [5-7]. HBO has also become widely used as an adjunctive treatment for a variety of challenging medical conditions, including arterial gas embolism [8,9], carbon monoxide poisoning [10-12], delayed radiation injury [13-16], decompression sickness [17], problematic wounds [18], bone fractures [19], and liver dysfunction [20]. HBO appears to be generally safe for patients, as its side effects are rare and oxygen toxicity appears primarily when it is used at very high doses and for a longer duration than is recommended [4].

This review outlines the existing data regarding the medical use of HBO in cancer treatment, with a particular focus on the use of HBOT in the treatment of brain tumours and for prevention of late radiation injury in brain tissue.

\section{Hyperbaric oxygen therapy in cancer treatment}

One of the major issues contributing to ineffective medical treatment of cancer is the occurrence of local hypoxia within the central tumour areas. The application of HBOT may help overcome the problem of oxygen deficiency in the poorly oxygenated regions of the neoplastic tissue. To date, several reviews on the use of $\mathrm{HBO}$ in cancer treatment have been published $[2,21,22]$. The effect of this therapy on malignancy has been unclear for a long time. The first and foremost question was whether HBO inhibits tumour growth or perhaps even enhances growth and the ability to form metastases. This fear grew from the observation in previous research studies that HBOT has a confirmed stimulatory effect on the proliferation of fibroblasts and epithelial cells in wound healing [3, 23]. Initially, the impact of hyperbaric oxygen on cancer cells was not clearly defined, and the results of early studies were controversial. McMillan et al. [24] concluded that HBO suppresses the development of oral carcinoma during its induction phase, whereas HBO might promote tumour growth during the proliferation phase. Recently, the similar results were obtained by Doguchi et al. [25] who claimed that hyperbaric oxygenation enhances tumour cells proliferation and therefore promotes chemically induced skin carcinogenesis. Braks et al. [26] conducted in vivo study on head and neck squamous cell carcinoma in mouse model, which indicated that $\mathrm{HBO}$ alone can enhance tumour growth, hypoxia, and vascular permeability of non-irradiated tumours. No changes in time survival, metastasis, and malignancy of cancer were observed. However, it should be emphasized that in the presented studies time and frequency of oxygenation were greater than in most experimentally used protocols. Nevertheless, the current state of knowledge almost unequivocally states that $\mathrm{HBO}$ is not only unconducive to further cancer development, but even might reduce the main tumour mass [27, 28]. It has been documented that $\mathrm{HBO}$ contributes to reduced tumour hypoxia by raising the oxygen concentration in the blood plasma. Brizel et al. [29] performed in vivo studies on rats with implanted mammary adenocarcinoma. Animals divided into five groups were treated with inhaled normobaric or hyperbaric (3 ATA) oxygen or with normobaric or hyperbaric (3 ATA) carbogen (a gas mixture consisting of $95 \% \mathrm{O}_{2}$ and $5 \% \mathrm{CO}_{2}$ ). There was no significant improvement in tumour oxygenation in groups exposed to either normobaric oxygen or carbogen. However, positive results were observed in the groups treated with high-pressure gases. The latest analogical study was conducted by Thews and Vaupel [30]. They tested an influence of normo- and hyperbaric hyperoxygenation (pure oxygen or carbogen) on local hypoxic regions occurrence and spatial $\mathrm{pO}_{2}$ distribution using DS-sarcoma cell line injected subcutaneously in rats. While in standard conditions (1 atm) hyperoxia only slightly enhanced tumour oxygenation in comparison with normal air, under pressure of $2 \mathrm{~atm}$ median $\mathrm{pO}_{2}$ was fivefold higher. After hyperbaric oxygen as well as hyperbaric carbogen administration, the spatial $\mathrm{pO}_{2}$ distribution profiles showed almost absolute elimination of hypoxic regions, even in the large tumours. However, HBO alone gives a limited curative effect and is typically not applied by itself. More often, HBO is used as an adjuvant treatment along with other therapeutic modalities, such as radio-, chemo-, and photodynamic therapy. Recently, Poff et al. [31] proposed also non-toxic, metabolic anti-cancer therapy based on ketonic diet, ketone supplementation, and hyperbaric oxygen combination. When used during surgical procedures, HBO helps to speed the convalescence and healing of wounds, and it minimizes surgical pain [32].

\section{Hyperbaric oxygen as an radiotherapy adjuvant}

Radiotherapy (RT) utilizes the so-called classical oxygen effect in tumour treatment. Upon exposure to radiation, water molecules undergo radiolysis to form unstable hydrogen and hydroxyl radicals. Hydrogen radicals react with molecular oxygen, yielding unstable perhydroxyl radicals and hydrogen peroxide, which cause serious DNA strand 
damage and consequently lead to cell death [33]. Thus, radiation treatment gives an optimal therapeutic result in well-oxygenated tumour tissue. It was observed that mice breathing pure $1 \mathrm{~atm}$ oxygen required a one-third smaller dose of X-rays than mice that were breathing air to achieve similar cancer regression [34]. HBO might play two possible roles when combined with RT: it may act as a radiosensitizer, which enhances the effect of radiation, or it may act as a therapeutic agent, reducing delayed radiation injury [13-16]. A combination of HBO and radiotherapy reduces tumour growth and improves local tumour control, resulting in increased survival time [21, 35]. Watson et al. [36] conducted clinical trial on 320 cervical carcinoma patients to investigate the influence of radiation in combination with HBO. Both local tumour control and patient survival in the HBO group were significantly better than in the control normobaric group. HBO had additional impressive positive effects: oxygen therapy abolished negative side effects of RT such as the accompanying postradiation injury of normal tissue. Similar results were obtained by Cade and McEwen, who enrolled 505 patients with various types of cancer into a clinical trial investigating the impact of HBO with radiotherapy [37]. Low doses of radiation provided a weak therapeutic effect; however, administration of a maximum dose along with high-pressure oxygen improved the survival of the patients with cervical or bronchial carcinoma in comparison with patients who were irradiated in normal air. However, the combined therapy did not affect patients with bladder tumours [37]. Also, Henk et al. [38] obtained similar negative results in a clinical trial of head and neck cancer treatment in which HBO was used as a radiosensitizer. In this trial, the survival time was similar regardless of whether the patients were breathing oxygen under elevated pressure or normobaric air; however, local control of the tumour was improved in the HBO-treated group. In further studies, Henk et al. [39] observed a significant improvement in patient survival (60 vs. $30 \%$ ) and tumour local control (63 vs. $30 \%$ ) with radiation treatment in $\mathrm{HBO}$ or air. Some other research groups, who conducted similar independent experiments, noted a high prevalence of severe late complications [40-43]. Other recent reports suggest that HBO treatment of patients with cancers of the head and neck improves not only local tumour control but also the overall outcome and that the side effects observed previously were caused by excessive radiation doses per fraction [35, 44].

\section{Hyperbaric oxygen as a chemotherapy adjuvant}

The mechanism of action of certain cytostatic drugs is based on the production of reactive oxygen species (ROS). ROS are formed as a result of oxidative stress in eukaryotic cells, triggered by either insufficient or excessive levels of oxygen in tissue, by radiation, by toxins, or by other adverse factors [33]. ROS cause cellular damage via oxidation, and this has been implicated in the pathogenesis of many diseases. Increased production of ROS results in DNA strand damage, apoptosis, and cell death. However, the very frequent DNA mutations and impairment of apoptosis lead to the development of highly anaplastic, therapy-resistant, neoplastic cells that are capable of causing local tumour recurrence and/or distant metastases. Moreover, cancer cells develop effective mechanisms that can help them to avoid the toxic effects of free radicals, although the amount of ROS tolerated by neoplastic cells is limited and above certain levels of oxidative stress or during prolonged exposure, the self-defence mechanisms become overwhelmed and cell death occurs [2]. Administration of HBO can be therapeutically advantageous by providing additional oxygen molecules and thereby increasing chemotherapy-generated oxidative stress. In addition, the transport of cytostatic agents is hindered by poor tissue perfusion [2, 45]. HBO treatment overcomes tissue hypoxia and promotes the development of new blood vessels, which are then able to transport drug molecules, thereby rendering the tumour cells more sensitive to chemotherapeutic treatments. Several studies have been conducted to examine the impact of hyperbaric oxygen as an adjuvant agent for use with chemotherapy [46-60]. Kalns et al. [47] found that the effect of hyperbaric oxygen on the proliferation and sensitivity to chemotherapy of prostate cancer cells in vitro were dependent on the type of cell line. Alazog et al. [46] examined the effect of cisplatin treatment on ovarian cancer in mice xenografts under HBO administration and found that HBO improved tumour vascularization and, when combined with cisplatin, diminished the tumour growth more effectively than cisplatin alone. Similar results were also obtained by Selvendiran et al. [58]; however, the authors believed that the remarkable lessening of the tumour volume was mostly associated with a dramatic reduction in overall body weight in the cisplatin-HBO group. The probable cause was an extreme increase in cisplatin toxicity triggered by hyperbaric oxygen, which led the authors to conclude that the combination of cisplatin and HBO should be avoided. In a study performed on sarcoma cells in vivo, Takiguchi et al. [48] assessed the therapeutic impact of HBO alone as well as in combination with 5-fluorouracil (5-FU). They found only a slight difference in tumour size between the control and the HBO monotherapy group. In contrast, the combination of 5-FU and HBO together significantly slowed the progression of tumour growth in comparison with the both the control group and the group treated with administration of 5-FU alone. Moreover, Stuhr et al. [50] observed that the combination of 5-FU and $\mathrm{HBO}$ can cause regression of 
mammary tumours. Moen et al. evaluated the influence of HBO on the uptake of 5-fluorouracil in an in vivo model of mammary adenocarcinoma in rats. Three groups were studied: a control group under atmospheric conditions (defined by the authors as 1 bar), a group subjected to a single $\mathrm{HBO}$ treatment $\left(\mathrm{pO}_{2}=2\right.$ bar), and a group subjected to repeated $\mathrm{HBO}$ treatments $\left(\mathrm{pO}_{2}=2\right.$ bar, single treatment every third day of experiment, four series in total) [56]. Administration of a single dose of HBO caused 5-FU uptake into the tumour tissue to rise, as measured immediately after oxygenation. No differences were observed between the control group and the group with the repeated $\mathrm{HBO}$ treatments, although it is noted that the measurements of 5-FU uptake of the third group were taken $24 \mathrm{~h}$ after the last HBO session, which may be too long a time lag to observe any effects, as the $\mathrm{pO}_{2}$ increase in tissue lasted for only about $60 \mathrm{~min}$. Ohguri et al. [60] proposed to combine hyperbaric oxygen with carboplatin and mild hyperthermia (HT). After using carboplatin-mild HT-HBO treatment sequence, the tumour growth was slowed down and its size was reduced. It may be concluded that HBO might be a promising chemotherapy adjuvant, although its observed effectiveness depends strongly upon the cytotoxic agent and the experimental conditions under which is it measured, as well as the type of the tumour.

\section{Hyperbaric oxygen therapy in malignant glioma treatment}

Gliomas are the most common primary brain tumours, derived from astroglial cells. The highly malignant tumour, glioblastoma (GBM), is characterized by aggressive biology and infiltrative growth. The standard treatment for glioblastoma includes surgical intervention, radiotherapy, and chemotherapy. Despite continuous advancements in treatment strategies, the prognosis for malignant glioma patients remains poor. Median survival after GBM diagnosis is about 12 months and $<15 \%$ of patients live more than 2 years [61]. Even the administration of temozolomide (TMZ), the chemotherapeutic agent most commonly used for gliomas, extends expected survival by only 2 months. It is thought that one of the pivotal factors responsible for treatment failure is tumour hypoxia, which is a state of reduced oxygen availability, or decreased oxygen partial pressure, that restricts or even abolishes cell functions [62]. Neoplastic proliferation induces rapid tumour growth, associated with dysregulated and faulty angiogenesis, resulting in a condition in which the neoplastic cells that are located in deeper regions of the tumour are poorly supplied with oxygen [62, 63]. Such cells migrate along the pathway of white matter to reach the better oxygenated brain areas proximal to blood vessels.
Moreover, the hypoxia itself activates mechanisms responsible for formation of abnormal blood vessels. Therefore, invasion of neoplastic cells into the normal brain tissue and faulty angiogenesis establish two so-called vicious circles, in which a major causative role can be ascribed to the occurrence of local hypoxic regions within the tumour mass $[63,64]$. Whereas hypoxia is toxic to normal cells, causing their apoptotic and necrotic death, neoplastic cells acquire the ability to develop defence mechanisms that allow them to survive under conditions of oxygen deprivation [2, 64]. The partial pressure of oxygen differs within normal tissues and solid tumours and is between 24 and $66 \mathrm{mmHg}$ and $2.5-30 \mathrm{mmHg}$, respectively [65]. Hypoxia triggers changes in the expression of proteins involved in the cell cycle, proliferation, metabolism, and apoptosis, which can exacerbate tumour malignancy [2]. Consequently, a high level of hypoxia is considered to be a negative prognostic factor with respect to patient survival and response to treatment. Poor vascularization and insufficient perfusion inside the tumour mass limit the action of cytostatic agents, as they reach distant tumour cells in lower concentrations than could otherwise be expected. The administration of higher doses of cytostatic drugs is not an alternative, due to their toxicity towards normal, healthy cells [2]. Oxygen deprivation also results in decreased efficiency of radiotherapy and phototherapy $[62,66]$. Therefore, to potentiate treatment, various strategies to overcome tumour hypoxia have been proposed, including inhibition of the expression of hypoxia inducible factors (HIFs), increasing the ability of red blood cells (RBCs) to carry oxygen (transfusions, administration of erythropoietin), and the use of artificial oxygen carriers (haemoglobin- or perfluorocarbon-based), radiosensitizers, bioreductive drugs, and gene therapy [65-68]. One of the most promising approaches to address the problem of tumour hypoxia appears to be HBOT.

Only a few reviews addressing the use of HBOT in patients with brain tumours have been published to date [69]. Kohshi et al. [70] focused on the therapeutic effects of $\mathrm{HBO}$ on brain tumours and tissue that has been injured by radiation. In normal brain tissue, oxygen is observed at approximately $25-50 \mathrm{mmHg}[71,72]$. It is well documented that inside brain tumours, as in other solid tumours, oxygen transport is seriously hindered and that local hypoxic regions develop. As has been mentioned previously, the application of HBO increases oxygen transport via blood plasma, independently from transport via haemoglobin. It has been experimentally demonstrated that inhibition of oxygen saturation of haemoglobin to a level of $75 \%$ induced the reduction in partial pressure of oxygen in the cerebral tissue of rats that were breathing air, whereas no $\mathrm{pO}_{2}$ changes were detected in rats that were breathing high-pressure oxygen [73]. A positive impact of $\mathrm{HBO}$ on 
the oxygenation of brain tissue can be observed both in the normal brain as well as in glioblastoma tissue; the oxygen level can rise by as much as $100-115 \%$ upon HBO exposure [74]. Beppu et al. [75] measured peritumoral and intratumoral $\mathrm{pO}_{2}$ in patients with glioblastoma under different conditions. The mean intratumoral $\mathrm{pO}_{2}$ level was $9.2 \pm 5.8 \mathrm{mmHg}$, which is consistent with the findings obtained in earlier studies [76, 77]. Hyperbaric oxygenation caused an elevation in $\mathrm{pO}_{2}$ levels in the tissue most closely surrounding the tumour and in the tumour interior, and in both of these the $\mathrm{pO}_{2}$ level remained greater than $30 \mathrm{mmHg}$ for $15 \mathrm{~min}$ after decompression [75].

Stuhr et al. [78] elucidated the effects of hyperbaric oxygen alone on BT4C rat glioma xenografts in vivo. Groups of eight animals were treated with $100 \% \mathrm{O}_{2}$ under normobaric conditions or under higher pressure (of 2 bar), or kept under normal air conditions as the control. Hyperoxia (both normo- and hyperbaric) resulted in a $60 \%$ retardation of tumour growth in comparison with tumour growth in the controls. Additionally, such tumours showed a greater number of "empty" vacuole spaces and necrotic areas, with $20 \%$ more apoptotic cells than were observed in control tumours, although it was notable that the proliferation rate of cells remained unchanged. Under both hyperoxia conditions, gene profile analysis revealed induction of several pro-apoptotic genes (GzmG, Gridl, Ceacaml) and proliferation inhibitors (Gaplgal), as well as reduction in the expression of several anti-apoptotic (Accn1, Nup62, Psen1), pro-proliferation (Hyal4, Sn5atp9), and pro-angiogenic genes (Hif $2 \alpha$, Efnal). HBO did not cause damage of normal tissues. Inconsistent observations were made by Wang et al. [79]. Administration of $\mathrm{HBO}$ to intracranial transplanted glioma mouse model caused intensification of tumour growth as well as glioma cells proliferation and angiogenesis. However, apoptosis of neoplastic cells was significantly higher in $\mathrm{HBO}$ group than in control. Ding et al. also pointed out to the potentially hazardous consequences of HBO treatment like increased tumour volume and angiogenesis, likewise apoptosis inhibition [80]. Nevertheless, once again HBO procedures employed to the mentioned studies were more intensive than previously used. Such discrepancy might result also from using the intracranial glioma models, while so far experiments were carried out on subcutaneous transplanted glioma cells.

Independently of uncertain beneficial effect of $\mathrm{HBO}$ alone, its combination with radio- and/or chemotherapy appeared advantageous. Chang investigated whether the application of HBO during irradiation might improve the curative effect of radiotherapy on glioma treatment [81]. The median survival time of the patients in the HBO group was 38 weeks, in comparison with 31 weeks for patients in the control group, and survival rates after 18 months were 28 and $10 \%$, respectively. Dowling et al. conducted a pilot study to investigate the hypothesis that a combination of perfluorochemicals with hyperbaric oxygen as adjunct for radiation may have more beneficial impact than either adjuvant therapy alone [82]. Sixteen of the 20 patients with anaplastic astrocytoma or glioblastoma, who received Fluosol prior to irradiation in a HBO atmosphere, completed the medical treatment with no symptoms of oxygen toxicity. Despite enthusiasm generated by the outcomes of the trials reviewed above, the effect of HBO simultaneously applied with radiotherapy turned out to be complicated, as it resulted in late side effects, including radiation necrosis and seizures [83]. Kohshi et al. [83] proposed a variant approach, in which patients were irradiated immediately after decompression from the $\mathrm{HBO}$ conditions. Although reduction in high-grade gliomas was observed in $33 \%$ of the patients in the control irradiated group, they all suffered recurrences and died within 36 months after radiotherapy. In the group treated with $\mathrm{HBO}$ and RT, more than $50 \%$ tumour regression was observed, and in four of the nine patients with anaplastic astrocytoma the disappearance of the tumour lesions was demonstrated by neuroimaging. Three patients from the HBO-treated group died due to neoplastic development during the period of observation. Kohshi et al. [84] further investigated the optimal time window during which external beam radiotherapy should be applied after hyperbaric oxygenation to achieve the desired therapeutic effect of treatment of patients with malignant gliomas. The median survival was observed to be twice as long in the hyperbaric groups than in the control group. Greater than $50 \%$ tumour regression was observed in patients who received RT 15 min after decompression. In the group receiving radiotherapy $30 \mathrm{~min}$ after decompression, no cancer regression occurred, but the tumours were stable during an 11-14 month followup period. The reason was postulated to be that the higher oxygen pressure in the tumour lasted only for a short time after oxygenation. Kohshi et al. [85] also examined the effect of combining $\mathrm{HBO}$ with fractionated stereotactic radiotherapy (FSRT) using a gamma unit. FSRT allows the precise, and therefore less invasive, administration of lower doses of radiation, which reduces damage to the normal tissue in the vicinity of tumour. The median survival time of patients treated with this protocol was observed to be 19 and 11 months for patients with anaplastic astrocytoma and glioblastoma, respectively. Bühler et al. [86] suggested that photon irradiation applied after $\mathrm{HBO}$ can extenuate glioblastoma cells survival and migration. Analysis of prospective studies on the influence of HBO followed by RT on high-grade glioma patients showed that proposed treatment is safe and gives promising therapeutic results [87].

In Japan, malignant glioma is most commonly treated with interferon beta, nimustine (ACNU), and radiation (IAR therapy). Beppu et al. [88] tested a modified IAR 
therapy protocol in which radiation was preceded by the administration of hyperbaric oxygen. A response to $\mathrm{HBO} /$ IAR treatment was observed in $10(50 \%)$ of the patients with glioblastoma and $3(30 \%)$ of the patients with anaplastic astrocytoma (43\% in total). Only in two cases was tumour progression noted. No correlation was made between response rates and other prognostic factors including age, Karnofsky performance scale (KPS), histological type of tumour, tumour size, and tumour location. The results suggested that HBO/IAR may be advantageous for patients with poor prognosis, who achieved comparable results to those with good prognosis. Meanwhile, Ogawa et al. conducted a prospective trial to investigate the feasibility and efficacy of radiotherapy after hyperbaric oxygenation used together with chemotherapy [89]. Patients with various kinds of malignant gliomas, including glioblastoma, anaplastic astrocytoma, anaplastic oligoastrocytoma, and anaplastic oligodendroglioma, were exposed to radiation treatment within $15 \mathrm{~min}$ after HBOT. In addition, they received the cytostatic agents, procarbazine, nimustine, and vincristine. A $69 \%$ positive response was observed, with no instance of disease progression. The one- and two-year overall survival rates were 83 and $56 \%$, respectively. The same team observed similar trends in further studies enlisting a larger group of patients [90]. A positive response was observed in $57 \%$ of the cases, and the median survival time for patients with glioblastoma was slightly prolonged from 11-15 months to 17.3 months in this study. However, acute toxicity developed in almost $48 \%$ of the patients in both trials. Nevertheless, grade 4 haematological toxicity and late radiation injuries were observed to be rare, and the use of this method is not precluded. Over the long term, the median survival time of patients treated with $\mathrm{HBO}$ followed by radiotherapy in combination with chemotherapy was 20.2 months, with a 17.2 and 113.4 months median observed for patients with glioblastoma and grade III gliomas, respectively [91].

To investigate the influence of HBO on the distribution of carboplatin in the brain, Suzuki et al. [92] used a rat model in which this cytostatic agent was administered intravenously. Under atmospheric conditions, they found the level of carboplatin in rat brains to be undetectable, as opposed to HBO-treated groups, in which the drug concentration could be established. The same research team evaluated the effectiveness of carboplatin combined with HBO for treatment of patients with gliomas [93]. HBO treatment resulted in a prolongation of the carboplatin mean residence time (MRT) in plasma. However, the effects observed in patients were diverse (from complete recovery or reduction of tumour mass to progression of disease) and also difficult to interpret, due to the small number of patients in each of the treatment groups. To assess the impact of HBOT on the therapeutic effect of temozolomide (TMZ), Dagistan et al. [94] conducted an experimental study on rats that had been injected with $\mathrm{C6}$ glioma cells. The results of this study suggested that the combination of TMZ and HBO significantly diminishes cell proliferation and angiogenesis and that it also stimulates apoptosis of glioma cells, in comparison with the control group and the group treated with TMZ alone. The potential influence of HBO on TMZ cytotoxicity was independently examined by Lu et al. [95] in in vitro trials. The human glioma U251 cell line was incubated under various therapeutic conditions: control, HBO alone, temozolomide alone, and temozolomide plus HBO. Analysis of the outcomes showed that combined TMZ/HBO therapy provided significantly better cell growth inhibition, compared to HBO alone, which elicited no changes. HBO also induced apoptosis of neoplastic cells. Furthermore, the mean rate of apoptosis was found to be over two and four times greater in the TMZ-treated and the TMZ/HBO group, respectively, compared to controls. A similar effect was observed with regard to cell viability; the TMZ group exhibited a fourfold increase in per cent of dead cells, compared to the control group, while in the TMZ/HBO group the percentage of dead cells was increased sixfold. Decreased VEGF and MRP-1 protein levels that were observed in the $\mathrm{HBO}$ and TMZ/HBO experimental groups suggested that $\mathrm{HBO}$ may elicit its effect through two pathways: inhibition of angiogenesis and diminution of drug resistance.

\section{Final conclusions}

Hypoxic regions within the tumour mass play a major role in tumour development and resistance to novel radio- and chemotherapies. HBOT holds promise as an approach to overcoming oxygen insufficiency by increasing the oxygen supply to neoplastic tissue. Recent results strongly indicate that $\mathrm{HBO}$ does not induce cancer growth, recurrence, or metastasis. Indeed, HBO is observed to exert an inhibitory effect on cancer cell proliferation and to stimulate cancer cell apoptosis. However, the beneficial effect of $\mathrm{HBO}$ is diverse, and it varies with the tumour type, malignancy, size of the lesion, and the clinical state of the patient. It is dependent on the specifics of the oxygenation protocol, and consequently it is very important to establish the proper moment of application, duration, pressure, and number of doses.

We conclude that the administration of HBO can provide many clinical benefits in the treatment of tumours, including management of highly malignant gliomas. Applied immediately before irradiation, it is safe and well tolerated by patients, causing rare and limited side effects. 
The results obtained with a combination of $\mathrm{HBO} /$ radiotherapy protocol proved to be especially favourable compared to radiation treatment alone. HBO can also increase the cytostatic effect of certain drugs, which may render standard chemotherapy more effective. The currently available data support the legitimacy of conducting further research on the use of $\mathrm{HBO}$ in the treatment of malignancies.

Acknowledgments The research was supported by the Leading National Research Centre-Mossakowski Medical Research Centre (KNOW-MMRC) Project.

\section{Compliance with ethical standards}

Conflict of interest The authors declare that they have no conflict of interest.

Open Access This article is distributed under the terms of the Creative Commons Attribution 4.0 International License (http://crea tivecommons.org/licenses/by/4.0/), which permits unrestricted use, distribution, and reproduction in any medium, provided you give appropriate credit to the original author(s) and the source, provide a link to the Creative Commons license, and indicate if changes were made.

\section{References}

1. Jain KK. Physical, physiological, and biochemical aspects of hyperbaric oxygenation. In: Jain KK, editor. Textbook of hyperbaric medicine. Germany: Hogrefe \& Huber; 2009. p. 9-20.

2. Daruwalla J, Christophi C. Hyperbaric oxygen therapy for malignancy: a review. World J Surg. 2006;30(12):2112-31. doi:10.1007/s00268-006-0190-6.

3. Gill AL, Bell CN. Hyperbaric oxygen: its uses, mechanisms of action and outcomes. QJM. 2004;97(7):385-95.

4. Tibbles PM, Edelsberg JS. Hyperbaric-oxygen therapy. N Engl J Med. 1996;334(25):1642-8. doi:10.1056/NEJM199606203342506.

5. Chaves JC, Fagundes DJ, Simoes Mde J, Bertoletto PR, Oshima CT, Taha MO, et al. Hyperbaric oxygen therapy protects the liver from apoptosis caused by ischemia-reperfusion injury in rats. Microsurgery. 2009;29(7):578-83. doi:10.1002/micr.20664.

6. Ilhan H, Eroglu M, Inal V, Eyi YE, Arziman I, Yildirim AO, et al. Hyperbaric oxygen therapy alleviates oxidative stress and tissue injury in renal ischemia/reperfusion injury in rats. Ren Fail. 2012;34(10):1305-8. doi:10.3109/0886022X.2012.723776.

7. Losada DM, Chies AB, Feres O, Chaib E, D'Albuquerque LA, Castro-e-Silva O. Effects of hyperbaric oxygen therapy as hepatic preconditioning in rats submitted to hepatic ischemia/reperfusion injury. Acta Cir Bras. 2014;29(Suppl 2):61-6.

8. Benson J, Adkinson C, Collier R. Hyperbaric oxygen therapy of iatrogenic cerebral arterial gas embolism. Undersea Hyperb Med. 2003;30(2):117-26.

9. Murphy BP, Harford FJ, Cramer FS. Cerebral air embolism resulting from invasive medical procedures. Treatment with hyperbaric oxygen. Ann Surg. 1985;201(2):242-5.

10. Raphael JC, Elkharrat D, Jars-Guincestre MC, Chastang C, Chasles V, Vercken JB, et al. Trial of normobaric and hyperbaric oxygen for acute carbon monoxide intoxication. Lancet. 1989;2(8660):414-9.

11. Buckley NA, Juurlink DN, Isbister G, Bennett MH, Lavonas EJ. Hyperbaric oxygen for carbon monoxide poisoning. Cochrane
Database Syst Rev. 2011;4:CD002041. doi:10.1002/14651858. CD002041.pub3.

12. Weaver LK, Hopkins RO, Chan KJ, Churchill S, Elliott CG, Clemmer TP, et al. Hyperbaric oxygen for acute carbon monoxide poisoning. N Engl J Med. 2002;347(14):1057-67. doi:10.1056/NEJMoa013121.

13. Mayer R, Hamilton-Farrell MR, van der Kleij AJ, Schmutz J, Granstrom G, Sicko Z, et al. Hyperbaric oxygen and radiotherapy. Strahlenther Onkol. 2005;181(2):113-23. doi:10.1007/ s00066-005-1277-y.

14. Pasquier D, Hoelscher T, Schmutz J, Dische S, Mathieu D, Baumann M, et al. Hyperbaric oxygen therapy in the treatment of radio-induced lesions in normal tissues: a literature review. Radiother Oncol. 2004;72(1):1-13. doi:10.1016/j.radonc.2004. 04.005.

15. Williamson RA. An experimental study of the use of hyperbaric oxygen to reduce the side effects of radiation treatment for malignant disease. Int $\mathrm{J}$ Oral Maxillofac Surg. 2007;36(6):533-40. doi:10.1016/j.ijom.2007.03.003.

16. Bennett MH, Feldmeier J, Hampson N, Smee R, Milross C. Hyperbaric oxygen therapy for late radiation tissue injury. Cochrane Database Syst Rev. 2012;5:CD005005. doi:10.1002/ 14651858.CD005005.pub3.

17. Stipp W. Time to treatment for decompression illness. Research report RR 550, Health and Safety Executive Books; 2007. p. 1-29.

18. Grundmann T, Jaehne M, Fritze G. The value of hyperbaric oxygen therapy $(\mathrm{HBO})$ in treatment of problem wounds in the area of plastic-reconstructive head and neck surgery. Laryngorhinootologie. 2000;79(5):304-10. doi:10.1055/s-2000-8802.

19. Wu D, Malda J, Crawford R, Xiao Y. Effects of hyperbaric oxygen on proliferation and differentiation of osteoblasts from human alveolar bone. Connect Tissue Res. 2007;48(4):206-13. doi:10.1080/03008200701458749.

20. Mizuguchi T, Oshima H, Imaizumi H, Kohara H, Kawamoto M, Nobuoka T, et al. Hyperbaric oxygen stimulates cell proliferation and normalizes multidrug resistance protein- 2 protein localization in primary rat hepatocytes. Wound Repair Regen. 2005;13(6):551-7. doi:10.1111/j.1524-475X.2005.00077.x.

21. Al-Waili NS, Butler GJ, Beale J, Hamilton RW, Lee BY, Lucas P. Hyperbaric oxygen and malignancies: a potential role in radiotherapy, chemotherapy, tumor surgery and phototherapy. Med Sci Monit. 2005;11(9):RA279-89.

22. Moen I, Stuhr LE. Hyperbaric oxygen therapy and cancer-a review. Target Oncol. 2012;7(4):233-42. doi:10.1007/s11523012-0233-x.

23. Tompach PC, Lew D, Stoll JL. Cell response to hyperbaric oxygen treatment. Int J Oral Maxillofac Surg. 1997;26(2):82-6.

24. McMillan T, Calhoun KH, Mader JT, Stiernberg CM, Rajaraman $\mathrm{S}$. The effect of hyperbaric oxygen therapy of oral mucosal carcinoma. Laryngoscope. 1989;99(3):241-4.

25. Doguchi H, Saio M, Kuniyoshi S, Matsuzaki A, Yoshimi N. The enhancing effects of hyperbaric oxygen on mouse skin carcinogenesis. J Toxicol Pathol. 2014;27(1):67-72. doi:10.1293/tox. 2013-0046.

26. Braks JA, Spiegelberg L, Koljenovic S, Ridwan Y, Keereweer S, Kanaar R, et al. Optical imaging of tumor response to hyperbaric oxygen treatment and irradiation in an orthotopic mouse model of head and neck squamous cell carcinoma. Mol Imaging Biol. 2015;17(5):633-42. doi:10.1007/s11307-015-0834-8.

27. Feldmeier J, Carl U, Hartmann K, Sminia P. Hyperbaric oxygen: does it promote growth or recurrence of malignancy? Undersea Hyperb Med. 2003;30(1):1-18.

28. Tang H, Sun Y, Xu C, Zhou T, Gao X, Wang L. Effects of hyperbaric oxygen therapy on tumor growth in murine model of PC-3 prostate cancer cell line. Urology. 2009;73(1):205-8. doi:10.1016/j.urology.2008.04.057. 
29. Brizel DM, Lin S, Johnson JL, Brooks J, Dewhirst MW, Piantadosi CA. The mechanisms by which hyperbaric oxygen and carbogen improve tumour oxygenation. $\mathrm{Br} \mathrm{J}$ Cancer. 1995;72(5):1120-4.

30. Thews O, Vaupel P. Spatial oxygenation profiles in tumors during normo- and hyperbaric hyperoxia. Strahlenther Onkol. 2015;191(11):875-82. doi:10.1007/s00066-015-0867-6.

31. Poff AM, Ward N, Seyfried TN, Arnold P, D'Agostino DP. Nontoxic metabolic management of metastatic cancer in VM mice: novel combination of ketogenic diet, ketone supplementation, and hyperbaric oxygen therapy. PLoS One. 2015;10(6):e0127407. doi:10.1371/journal.pone.0127407.

32. Carl UM, Feldmeier JJ, Schmitt G, Hartmann KA. Hyperbaric oxygen therapy for late sequelae in women receiving radiation after breast-conserving surgery. Int J Radiat Oncol Biol Phys. 2001;49(4):1029-31.

33. Halliwell B. Free radicals and other reactive species in disease. In: eLS. Chichester: John Wiley \& Sons Ltd; 2015. p. 1-9.

34. Gray LH, Conger AD, Ebert M, Hornsey S, Scott OC. The concentration of oxygen dissolved in tissues at the time of irradiation as a factor in radiotherapy. Br J Radiol. 1953;26(312):638-48.

35. Bennett MH, Feldmeier J, Smee R, Milross C. Hyperbaric oxygenation for tumour sensitisation to radiotherapy. Cochrane Database Syst Rev. 2012;4:CD005007. doi:10.1002/14651858. CD005007.pub3.

36. Watson ER, Halnan KE, Dische S, Saunders MI, Cade IS, McEwen JB, et al. Hyperbaric oxygen and radiotherapy: a Medical Research Council trial in carcinoma of the cervix. Br J Radiol. 1978;51(611):879-87.

37. Cade IS, McEwen JB. Clinical trials of radiotherapy in hyperbaric oxygen at Portsmouth, 1964-1976. Clin Radiol. 1978;29(3):333-8.

38. Henk JM, Kunkler PB, Smith CW. Radiotherapy and hyperbaric oxygen in head and neck cancer: final report of first controlled clinical trial. Lancet. 1977;2(8029):101-3.

39. Henk JM. Late results of a trial of hyperbaric oxygen and radiotherapy in head and neck cancer: a rationale for hypoxic cell sensitizers? Int J Radiat Oncol Biol Phys. 1986;12(8):1339-41.

40. Haffty BG, Hurley R, Peters LJ. Radiation therapy with hyperbaric oxygen at 4 atmospheres pressure in the management of squamous cell carcinoma of the head and neck: results of a randomized clinical trial. Cancer J Sci Am. 1999;5(6):341-7.

41. Haffty BG, Hurley RA, Peters LG. Carcinoma of the larynx treated with hypofractionated radiation and hyperbaric oxygen: long-term tumor control and complications. Int $\mathrm{J}$ Radiat Oncol Biol Phys. 1999;45(1):13-20.

42. Sun TB, Chen RL, Hsu YH. The effect of hyperbaric oxygen on human oral cancer cells. Undersea Hyperb Med. 2004;31(2):251-60.

43. Shi Y, Lee CS, Wu J, Koch CJ, Thom SR, Maity A, et al. Effects of hyperbaric oxygen exposure on experimental head and neck tumor growth, oxygenation, and vasculature. Head Neck. 2005;27(5):362-9. doi:10.1002/hed.20169.

44. Overgaard J. Hypoxic modification of radiotherapy in squamous cell carcinoma of the head and neck-a systematic review and meta-analysis. Radiother Oncol. 2011;100(1):22-32. doi:10. 1016/j.radonc.2011.03.004.

45. Baish JW, Gazit Y, Berk DA, Nozue M, Baxter LT, Jain RK. Role of tumor vascular architecture in nutrient and drug delivery: an invasion percolation-based network model. Microvasc Res. 1996;51(3):327-46. doi:10.1006/mvre.1996.0031.

46. Alagoz T, Buller RE, Anderson B, Terrell KL, Squatrito RC, Niemann $\mathrm{TH}$, et al. Evaluation of hyperbaric oxygen as a chemosensitizer in the treatment of epithelial ovarian cancer in xenografts in mice. Cancer. 1995;75(9):2313-22.
47. Kalns J, Krock L, Piepmeier E Jr. The effect of hyperbaric oxygen on growth and chemosensitivity of metastatic prostate cancer. Anticancer Res. 1998;18(1A):363-7.

48. Takiguchi N, Saito N, Nunomura M, Kouda K, Oda K, Furuyama $\mathrm{N}$, et al. Use of 5-FU plus hyperbaric oxygen for treating malignant tumors: evaluation of antitumor effect and measurement of 5-FU in individual organs. Cancer Chemother Pharmacol. 2001;47(1):11-4. doi:10.1007/s002800000190.

49. Petre PM, Baciewicz FA Jr, Tigan S, Spears JR. Hyperbaric oxygen as a chemotherapy adjuvant in the treatment of metastatic lung tumors in a rat model. J Thorac Cardiovasc Surg. 2003;125(1):85-95. doi:10.1067/mtc.2003.90.

50. Stuhr LE, Iversen VV, Straume O, Maehle BO, Reed RK. Hyperbaric oxygen alone or combined with 5-FU attenuates growth of DMBA-induced rat mammary tumors. Cancer Lett. 2004;210(1):35-40. doi:10.1016/j.canlet.2004.02.012.

51. Granowitz EV, Tonomura N, Benson RM, Katz DM, Band V, Makari-Judson GP, et al. Hyperbaric oxygen inhibits benign and malignant human mammary epithelial cell proliferation. Anticancer Res. 2005;25(6B):3833-42.

52. Heys SD, Smith IC, Ross JA, Gilbert FJ, Brooks J, Semple S, et al. A pilot study with long term follow up of hyperbaric oxygen pretreatment in patients with locally advanced breast cancer undergoing neo-adjuvant chemotherapy. Undersea Hyperb Med. 2006;33(1):33-43.

53. Daruwalla J, Greish K, Nikfarjam M, Millar I, MalcontentiWilson C, Iyer AK, et al. Evaluation of the effect of SMA-pirarubicin micelles on colorectal cancer liver metastases and of hyperbaric oxygen in CBA mice. J Drug Target. 2007;15(7-8):487-95. doi:10.1080/10611860701499839.

54. Ohguri T, Imada $H$, Narisada $H$, Yahara K, Morioka T, Nakano $\mathrm{K}$, et al. Systemic chemotherapy using paclitaxel and carboplatin plus regional hyperthermia and hyperbaric oxygen treatment for non-small cell lung cancer with multiple pulmonary metastases: preliminary results. Int J Hyperth. 2009;25(2):160-7. doi:10. 1080/02656730802610357.

55. Kawasoe Y, Yokouchi M, Ueno Y, Iwaya H, Yoshida H, Komiya $\mathrm{S}$. Hyperbaric oxygen as a chemotherapy adjuvant in the treatment of osteosarcoma. Oncol Rep. 2009;22(5):1045-50.

56. Moen I, Tronstad KJ, Kolmannskog O, Salvesen GS, Reed RK, Stuhr LE. Hyperoxia increases the uptake of 5-fluorouracil in mammary tumors independently of changes in interstitial fluid pressure and tumor stroma. BMC Cancer. 2009;9:446. doi:10. 1186/1471-2407-9-446.

57. Peng ZR, Zhong WH, Liu J, Xiao PT. Effects of the combination of hyperbaric oxygen and 5-fluorouracil on proliferation and metastasis of human nasopharyngeal carcinoma CNE-2Z cells. Undersea Hyperb Med. 2010;37(3):141-50.

58. Selvendiran K, Kuppusamy ML, Ahmed S, Bratasz A, Meenakshisundaram G, Rivera BK, et al. Oxygenation inhibits ovarian tumor growth by downregulating STAT3 and cyclin-D1 expressions. Cancer Biol Ther. 2010;10(4):386-90.

59. Ohgami Y, Elstad CA, Chung E, Shirachi DY, Quock RM, Lai HC. Effect of hyperbaric oxygen on the anticancer effect of artemisinin on molt-4 human leukemia cells. Anticancer Res. 2010;30(11):4467-70.

60. Ohguri T, Kunugita N, Yahara K, Imada H, Uemura H, Shinya N, et al. Efficacy of hyperbaric oxygen therapy combined with mild hyperthermia for improving the anti-tumour effects of carboplatin. Int J Hyperth. 2015;31(6):643-8. doi:10.3109/02656736. 2015.1055832.

61. Liang BC. Effects of hypoxia on drug resistance phenotype and genotype in human glioma cell lines. J Neurooncol. 1996;29(2):149-55. 
62. Hockel M, Vaupel P. Tumor hypoxia: definitions and current clinical, biologic, and molecular aspects. J Natl Cancer Inst. 2001;93(4):266-76.

63. Onishi M, Ichikawa T, Kurozumi K, Date I. Angiogenesis and invasion in glioma. Brain Tumor Pathol. 2011;28(1):13-24. doi:10.1007/s10014-010-0007-z.

64. Szala S, Jarosz M, Smolarczyk R, Cichon T. "Vicious circles" of glioblastoma tumors: vascularization and invasiveness. Postepy Hig Med Dosw. 2012;66:888-900. doi:10.5604/17322693.1019657.

65. Kizaka-Kondoh S, Inoue M, Harada H, Hiraoka M. Tumor hypoxia: a target for selective cancer therapy. Cancer Sci. 2003;94(12):1021-8.

66. Rockwell S, Dobrucki IT, Kim EY, Marrison ST, Vu VT. Hypoxia and radiation therapy: past history, ongoing research, and future promise. Curr Mol Med. 2009;9(4):442-58.

67. Henkel-Honke T, Oleck M. Artificial oxygen carriers: a current review. AANA J. 2007;75(3):205-11.

68. Biesaga B. Regulacja ekspresji białka HIF 1 jako nowa strategia celowanej terapii nowotworów złośliwych. Nowotw J Oncol. 2008;58(3):255-9.

69. Beppu T, Tanaka K, Kohshi K. Hyperbaric oxygenation for treatment of glioma. Gan To Kagaku Ryoho. 2011;38(6):933-6.

70. Kohshi K, Beppu T, Tanaka K, Ogawa K, Inoue O, Kukita I, et al. Potential roles of hyperbaric oxygenation in the treatments of brain tumors. Undersea Hyperb Med. 2013;40(4):351-62.

71. Dings J, Meixensberger J, Jager A, Roosen K. Clinical experience with 118 brain tissue oxygen partial pressure catheter probes. Neurosurgery. 1998;43(5):1082-95.

72. Carreau A, El Hafny-Rahbi B, Matejuk A, Grillon C, Kieda C. Why is the partial oxygen pressure of human tissues a crucial parameter? Small molecules and hypoxia. J Cell Mol Med. 2011;15(6):1239-53. doi:10.1111/j.1582-4934.2011.01258.x.

73. Jamieson D, Vandenbrenk HA. Measurement of oxygen tensions in cerebral tissues of rats exposed to high pressures of oxygen. J Appl Physiol. 1963;18:869-76.

74. Potapov AA, Rapman II, Liass FM, Manevich AZ, Iarmonenko SP. Oxygenation of glioblastomas and normal brain tissue during radiation therapy. Med Radiol. 1983;28(4):21-4.

75. Beppu T, Kamada K, Yoshida Y, Arai H, Ogasawara K, Ogawa A. Change of oxygen pressure in glioblastoma tissue under various conditions. J Neurooncol. 2002;58(1):47-52.

76. Kayama T, Yoshimoto T, Fujimoto S, Sakurai Y. Intratumoral oxygen pressure in malignant brain tumor. $\mathrm{J}$ Neurosurg. 1991;74(1):55-9. doi:10.3171/jns.1991.74.1.0055.

77. Cruickshank GS, Rampling RP, Cowans W. Direct measurement of the $\mathrm{pO}_{2}$ distribution in human malignant brain tumours. In: Vaupel P, et al., editors. Oxygen transport to tissue. New York: Plenum Press; 1994. p. 465-70.

78. Stuhr LE, Raa A, Oyan AM, Kalland KH, Sakariassen PO, Petersen K, et al. Hyperoxia retards growth and induces apoptosis, changes in vascular density and gene expression in transplanted gliomas in nude rats. J Neurooncol. 2007;85(2):191-202. doi:10.1007/s11060-007-9407-2.

79. Wang YG, Zhan YP, Pan SY, Wang HD, Zhang DX, Gao K, et al. Hyperbaric oxygen promotes malignant glioma cell growth and inhibits cell apoptosis. Oncol Lett. 2015;10(1):189-95. doi:10.3892/ol.2015.3244

80. Ding JB, Chen JR, Xu HZ, Qin ZY. Effect of hyperbaric oxygen on the growth of intracranial glioma in rats. Chin Med J. 2015;128(23):3197-203. doi:10.4103/0366-6999.170278.

81. Chang $\mathrm{CH}$. Hyperbaric oxygen and radiation therapy in the management of glioblastoma. Natl Cancer Inst Monogr. 1977;46:163-9.
82. Dowling S, Fischer JJ, Rockwell S. Fluosol and hyperbaric oxygen as an adjunct to radiation therapy in the treatment of malignant gliomas: a pilot study. Biomater Artif Cells Immobil Biotechnol. 1992;20(2-4):903-5.

83. Kohshi K, Kinoshita Y, Terashima H, Konda N, Yokota A, Soejima T. Radiotherapy after hyperbaric oxygenation for malignant gliomas: a pilot study. J Cancer Res Clin Oncol. 1996;122(11):676-8.

84. Kohshi K, Kinoshita Y, Imada H, Kunugita N, Abe H, Terashima $\mathrm{H}$, et al. Effects of radiotherapy after hyperbaric oxygenation on malignant gliomas. Br J Cancer. 1999;80(1-2):236-41. doi:10. 1038/sj.bjc.6690345.

85. Kohshi K, Yamamoto H, Nakahara A, Katoh T, Takagi M. Fractionated stereotactic radiotherapy using gamma unit after hyperbaric oxygenation on recurrent high-grade gliomas. J Neurooncol. 2007;82(3):297-303. doi:10.1007/s11060-006-9283-1.

86. Buhler H, Strohm GL, Nguemgo-Kouam P, Lamm H, Fakhrian $\mathrm{K}$, Adamietz IA. The therapeutic effect of photon irradiation on viable glioblastoma cells is reinforced by hyperbaric oxygen. Anticancer Res. 2015;35(4):1977-83.

87. Chen JR, Xu HZ, Ding JB, Qin ZY. Radiotherapy after hyperbaric oxygenation in malignant gliomas. Curr Med Res Opin. 2015;31(11):1977-84. doi:10.1185/03007995.2015.1082988.

88. Beppu T, Kamada K, Nakamura R, Oikawa H, Takeda M, Fukuda $\mathrm{T}$, et al. A phase II study of radiotherapy after hyperbaric oxygenation combined with interferon-beta and nimustine hydrochloride to treat supratentorial malignant gliomas. J Neurooncol. 2003;61(2):161-70.

89. Ogawa K, Yoshii Y, Inoue O, Toita T, Saito A, Kakinohana Y, et al. Prospective trial of radiotherapy after hyperbaric oxygenation with chemotherapy for high-grade gliomas. Radiother Oncol. 2003;67(1):63-7.

90. Ogawa K, Yoshii Y, Inoue O, Toita T, Saito A, Kakinohana Y, et al. Phase II trial of radiotherapy after hyperbaric oxygenation with chemotherapy for high-grade gliomas. $\mathrm{Br} \mathrm{J}$ Cancer. 2006;95(7):862-8. doi:10.1038/sj.bjc.6603342.

91. Ogawa K, Ishiuchi S, Inoue O, Yoshii Y, Saito A, Watanabe T, et al. Phase II trial of radiotherapy after hyperbaric oxygenation with multiagent chemotherapy (procarbazine, nimustine, and vincristine) for high-grade gliomas: long-term results. Int J Radiat Oncol Biol Phys. 2012;82(2):732-8. doi:10.1016/j.ijrobp.2010. 12.070 .

92. Suzuki Y, Tanaka K, Neghishi D, Shimizu M, Murayama N, Hashimoto T, et al. Increased distribution of carboplatin, an anticancer agent, to rat brains with the aid of hyperbaric oxygenation. Xenobiotica. 2008;38(12):1471-5. doi:10.1080/00498250802 478313.

93. Suzuki Y, Tanaka K, Negishi D, Shimizu M, Yoshida Y, Hashimoto T, et al. Pharmacokinetic investigation of increased efficacy against malignant gliomas of carboplatin combined with hyperbaric oxygenation. Neurol Med Chir. 2009;49(5):193-7.

94. Dagistan Y, Karaca I, Bozkurt ER, Ozar E, Yagmurlu K, Toklu A, et al. Combination hyperbaric oxygen and temozolomide therapy in C6 rat glioma model. Acta Cir Bras. 2012;27(6):383-7.

95. Lu XY, Cao K, Li QY, Yuan ZC, Lu PS. The synergistic therapeutic effect of temozolomide and hyperbaric oxygen on glioma U251 cell lines is accompanied by alterations in vascular endothelial growth factor and multidrug resistance-associated protein-1 levels. J Int Med Res. 2012;40(3):995-1004. 